\title{
El diario: la escritura autobiográfica en su dimensión sociocultural y sus posibilidades cognoscitivas y creativas*
}

Fecha de recepción: 08 de marzo de 2017

Fecha de aprobación: 27 de junio de 2017

\section{Resumen}

La escritura diarística está inmersa en la vida personal y social de nuestra cultura como una herramienta de análisis social y un ejercicio de escritura personal. Este artículo de reflexión pretende exponer y describir algunos ejemplos de escrituras diaristas en distintos ámbitos y contextos que van desde la creación artística hasta los procesos de formación educativa; y de esta manera, intentar vislumbrar las potencialidades y aciertos que trae la escritura autobiográfica para los espacios subjetivos, cognitivos y creativos de los individuos.

Palabras clave: diario, autobiografía, subjetividad, aprendizaje, creación, educación.

Citar: González Otero, A. (enero-junio de 2017). El diario: La escritura autobiográfica en su dimensión sociocultural y sus posibilidades cognoscitivas y creativas. La Palabra, (30), 151 - 167. doi: https://doi.org/10.19053/01218530.n30.2017.6961

\section{Angélica González Otero}

Magíster en Literatura de la Universidad Javeriana de Bogotá. Docente investigadora Licenciatura en Lingüística y Literatura de la Universidad La Gran Colombia. angelica.gonzalez@ugc.edu.co

* Este artículo de reflexión es parte del proyecto de investigación en curso: El diario: la escritura autobiográfica en su dimensión sociocultural y sus posibilidades cognoscitivas y creativas, en la Universidad La Gran Colombia. 


\section{la palabra}

\section{The Diary: Autobiographical Writing in its Sociocultural Dimension, Cognitive and Creative Possibilities}

\section{Abstract}

Diary writing is immerse in the personal and social life of our culture as a tool for social analysis and a personal writing exercise. This reflection article presents and describes examples of diary writing in different contexts, ranging from artistic creation to educational processes, pointing out the potentialities of autobiographical writing for the subjective, cognitive and creative spaces of individuals.

Keywords: Diary, Autobiography, Subjectivity, Learning, Creation, Education.

\section{Le journal intime: 1'écriture autobiographique dans sa dimension socio- culturelle et ses possibilités cognitives et créatives}

\section{Résumé}

L'écriture d'un journal intime est en rapport avec la vie personnelle et sociale de notre culture et peut être conçu comme un outil d'analyse sociale et un exercice d'écriture personnelle. Nous nous proposons d'exposer et de décrire des exemples d'écritures de journaux intimes dans différents domaines et contextes: de la création artistique jusqu'aux processus de formation éducative. Ainsi, nous signalerons les puissances et atouts de l'écriture autobiographique pour les espaces subjectifs, cognitifs et créatifs des individus.

Mots-clés: journal intime, autobiographie, subjectivité, apprentissage, création, education. 


\section{El ejercicio autobiográfico rompe la soledad que ronda el desarraigo más trágico: el desarraigo de nosotros mismos.}

La tradición diarística en el campo literario e histórico, ha estado presente en la vida cultural de occidente; el cultivo del diario íntimo se extiende a través de los siglos como un ejercicio de escritura privado, donde se pueden encontrar diversidad de temáticas que van desde el relato viajero, las experiencias místicas de monjas que transcribían en diarios personales sus acercamientos a la divinidad, hasta la más anónima escritura del diarista común. De igual forma, muchos escritores consagrados han cultivado este género literario convirtiéndolo en un instrumento más de su escritura creativa. Actualmente, con la llegada de las tecnologías de la información, el diario ha tenido nuevas fronteras de significación que se asientan en el mundo digital, y la vida íntima se expone más que nunca en el ámbito público. Por esto, se hace necesario volver sobre este tipo de escritura autobiográfica, comenzando por entender y analizar sus posibilidades $\mathrm{y}$ aportes no solo a la memoria histórica de las sociedades, sino también a la vida individual de los seres en sus dimensiones cognoscentes, creativas y psicológicas. El diario íntimo es, sin duda, una fuente de registro escritural de procesos culturales y sociales de una nación. Lo íntimo es espejo de lo colectivo y refleja sus aspiraciones y necesidades.

Este artículo de reflexión analiza las oportunidades y retos que tiene el diario como escritura autobiográfica, tanto en los ámbitos de la creación literaria, como de la subjetividad individual y en los procesos educativos contemporáneos donde este tipo de escritura se ha utilizado como una herramienta para potencializar la formación integral de profesores $\mathrm{y}$ estudiantes.

Desde distintas perspectivas, el diario ha sido objeto de diferentes estudios interdisciplinarios de orden académico e investigativo, como fuente y registro de la memoria histórica y social; de igual modo, en los procesos de aprendizaje en las llamadas "biografías cognitivas" donde pedagogos y académicos lo han utilizado como método didáctico para los procesos de formación educativa. También, se han realizado muchos experimentos literarios e investigaciones acerca del valor y la vigencia de este tipo de escritura en países como España, Italia y Francia. En Italia, por ejemplo, se encuentra la llamada: "ciudad del diario", localizada en un pueblo de Toscana, fundada por Saverio Tutino, donde reposan más de 3,700 textos autobiográficos, entre ellos un gran número de diarios escritos por gentes de todas las clases y oficios. Philippe Lejeune es uno de los académicos que más ha estudiado el fenómeno de lo autobiográfico y ha utilizado el diario como instrumentos en la educación para adultos, entre otras prácticas educativas; su último trabajo estuvo direccionado a investigar los diarios íntimos escritos en la web. De igual forma, España ha sido un referente para Latinoamérica en el estudios de las formas de escritura autobiográfica a la cabeza de Anna Caballé; el centro de memoria autobiográfica de la universidad de Barcelona guarda un sinnúmero de material de escritura autobiográfica que da cuenta de la vida histórica y cultural de España.

En Latinoamérica, se ha ido avanzando en el estudio y en la recuperación de la importancia de este tipo de escritura; sobre todo, en México y Argentina que han priorizado en sus investigaciones académicas el tema de lo autobiográfico y su incidencia en las ciencias humanas, realizando trabajos destacados tanto en el campo literario como en el educativo. Por el contrario, en Colombia no existen sino trabajos aislados en estos temas y ha prevalecido el estudio de casos ejemplares y de biografías ilustres del siglo decimonónico. En 
el año 2008, se realizó el primer congreso sobre el género autobiográfico en la Universidad de los Andes donde se destacaron trabajos de diversas formas de escritura autobiográfica en estudios interdisciplinarios desde la historia, la psicología, la literatura, etc. ${ }^{1}$ De aquí, destaco una apuesta por construir memoria desde el presente a partir de relatos biográficos en clave de diarios, y que registran una huella histórica y cultural a partir de seres anónimos, viajeros, monjas, etc., que se nombran en la escritura, tanto desde sí mismos, como a partir de la memoria de los otros.

\section{El diario: algunos presupues- tos teóricos, dilemas y retos}

El diario se ha definido o configurado en la memoria colectiva como un ejercicio de escritura autobiográfica, anónima $\mathrm{y}$ marginal; muchas veces asociado a un tipo de escritura netamente femenina o un espacio de reflexión, que luego queda en el olvido o rezagado de las miradas externas. Le sumamos a esto que, el diario no ocupa estamentos privilegiados en la historia literaria como la novela, el cuento o la poesía; su importancia y excepcionalidad están más asociadas al vínculo que ejerce este tipo de escritura sobre quien lo escribe y quien lo atesora como un espacio que resguarda su mundo personal. Sobre esto, dice Margara Russoto (2008): “¿Cómo dominar el salvajismo de la experiencia con una comprensión posiblemente inventada? ¿Y cómo transcender dicha experiencia en un ámbito de significación mayor?" (p. 258). La respuesta podría estar en ese solitario ejercicio diarístico que se asume con valor transcendente, no solo para quién lo escribe sino también para quien decide asomarse a la lectura de este tipo de escritura. Es también un recurso, de los muchos que da el arte y la literatura, de asegurar la supervivencia de la experiencia vital a través de una merecida reflexión sobre ese cúmulo de actos que representan una vida y que azotan indiscriminadamente las horas.

Un dilema interesante, y que ha sobrevivido a los tiempos para pensar en el diario personal y su lugar en el mundo literario, lo señala Álvaro Luque Amo (2016). Se trata del debate entre dos autores estudiosos del tema: Philippe Lejeune (1994) y Paul de Man (1991). Por un lado, Lejeune ubica al lector del relato autobiográfico en una coincidencia con la vida relata$\mathrm{da}$, estableciendo un pacto de veracidad e identificación con ella; con Paul de Man, se piensa en el relato autobiográfico como una construcción ficcional, que enfrenta al lector a un mundo yoico que no debe ni necesita tener referentes con una realidad específica y una verdad de orden referencial. Sin embargo, para Luque (2016), esas son posturas complementarias y apoyan con sus argumentos, la literalidad de este tipo de expresiones escritas: "El texto autobiográfico sería capaz, al mismo tiempo, de mantener una correspondencia con el mundo real y de construir un yo que es puramente textual, ficticio, sometido a las leyes concretas de la escritura" (p. 283). Y concluye a favor de un pensamiento de apertura muy acorde con el mundo contemporáneo, donde la importancia de lo ficcional o los recursos referenciales son alimentados en un hibridaje que supera estas nociones limitadas; y el diario con sus múltiples recursos formales, integra este paralelo en textualidades diversas muy propias de su naturaleza experiencial y vital.

Ahora bien, el diario lo pensamos asociado a una propuesta llamada a la diversidad, de atmósferas estilísticas heterogéneas, lejanas de una clasificación formal o de tipologías

\footnotetext{
1 Estas memorias reposan en el libro titulado: Relatos autobiográficos y otras formas del yo (2010). El libro tiene como compiladoras a las académicas: Carmen Elisa Acosta y Carolina Álzate y recorre diversos temas de la literatura colombiana que se enmarcan en el mundo de lo autobiográfico, algunos desde una perspectiva feminista con ejemplos de mujeres escritoras como Soledad Acosta de Samper (Autobiografía intelectual en Soledad A. de Samper) hasta relatos de mujeres Nasa (Cacicas del siglo XXI. Historia de vida de mujeres nasa).
} 
limitantes. Hace vecindad relativa y armoniosa con el campo epistolar, las memorias y la misma escritura biográfica, donde se da cuenta de la vida histórica y cronológica de un individuo particular. La escritura de un diario no posee parámetros exactos de convenciones escriturales, sino, al contrario, un abanico de formas cambiantes donde la escritura se adapta al sujeto y se muestra flexible ante el hecho de describir una situación ya sea de orden interior, cotidiana o reflexiva. ${ }^{2}$ De esta manera, no existe un género más adaptable, pero a la vez más exigente, en cuanto a esa correlación que debe existir entre lo que se hace necesario escribir y lo que resulta en la escritura formal. Por esto, un poema, una frase fragmentaria, el relato de un acontecimiento, $\mathrm{o}$ la expresión espontanea de una emoción; pueden encontrarse sin problema, habitando en el mismo espacio de la página de un diario.

Otra cuestión a reflexionar sería sobre esa categoría que asocia al diario al universo de lo íntimo; teniendo en cuenta que la expresión de "íntimo" puede resultar contradictoria y ambigua para este momento histórico ${ }^{3}$. La expresión "diario íntimo" comenzó a surgir en la academia francesa para referirse a un tipo de escritura en particular. Anna Caballé (1991) hace una aclaración al respecto:

En cualquier caso, la intimidad es un concepto que no debe identificarse con la práctica de registrar algo de lo que lleva en sí el día y cuyos contenidos han ido evolucionando a lo largo del tiempo. Si hay que calificar el diario es mucho mejor hablar de diario personal, para distinguirlo de otros ejercicios colectivos (los diarios de sesiones, por ejemplo). Pero un diario (personal) no tiene porqué ser íntimo (p. 19).

De igual forma, notamos que lo íntimo también está ligado a la noción de secreto, porque el diario se puede construir con base en un ejercicio donde nadie, excepto el diarista, está involucrado, y solo él puede hacer parte de ese espacio escritural, y solo él decide cuán privado desea conservarlo. El diario no es íntimo a priori, requiere de condiciones que aprueben su condición de intimidad. Por otro lado, si pensamos en la concepción de intimidad, nos remitimos a un ejercicio de conciencia de sí, a un diálogo entre el sí mismo y su vínculo con la escritura, y el diario puede apoyar la construcción de dicha intimidad, incentivar a gestarla; y es precisamente la palabra en su apuesta por la escritura, el material con

2 El diario como forma de expresión abierta es postulado por Beatrice Didier (1996): "el diario puede abrirse a cualquier cosa. El diarista puede integrar en su texto las facturas de la lavandería, recortes de periódico, fragmentos [...] a fin de cuentas todo (Didier, 1996, p. 39, citado en Diario personal en Literatura por Álvaro Luque Amo). De igual forma, Jordi Gracia expone ese carácter ambivalente y disperso del diario, su función muchas veces de catalizador de proyectos: "mucho de laboratorio de ideas literarias y de ejercicio en acto de esas ideas bailan en una zona fronteriza que asume su naturaleza de cuaderno privado" (Gracia, 2004, p. 223, citado en Diario personal en literatura por Álvaro Luque Amo). Incluso como lo expresa un escritor diarista la cercanía del diario a una integración genérica: "Si puede definirse el relato o la novela como una cristalización, el diario es más bien un mosaico: son los fragmentos de una explosión que sin embargo se dejan recomponer para dar lugar a un todo." (Trapiello, 1998, p. 25, citado en Diario personal en literatura por Álvaro Luque Amo). Finalmente, asumimos su condición de presente y cotidianidad, citada por Eric Bou (1996) como características intrínsecas del ejercicio diarista donde el yo puede expresar su particularidad de ser y estar en el mundo. Todo este panorama de revisión teórica es expuesto por Álvaro Luque Amo en un artículo muy completo sobre el asunto de lo literario en el diario personal y que enmarca gratamente este tipo de expresiones textuales en un ejercicio de innumerables posibilidades y de gran acogida en la circunstancias actuales.

3 Si bien encontramos con antelación, y por primera vez, en un libro publicado la denominación de "intimo" como lo cita Luque Amo (2016): "La publicación más importante es el Diario íntimo de Amiel, en tanto que influye y define la naturaleza de los diarios posteriores. El hecho de que sea la primera obra que emplea el término «íntimo» para definir al diario va a resultar paradójico si se tiene en cuenta que tras su publicación el paradigma del diario cambia, demostrando así la estrategia retórica que esa alusión a la intimidad va a conllevar en los primeros diarios del siglo XX. En el caso español, por ejemplo, Unamuno escribe su Diario íntimo en 1897 y lo escribe con la intención de publicarlo" (Luque Amo, 2016, p. 273). 
que se edifica ese estamento de lo íntimo.

Al lado del asunto conceptual de lo íntimo, se encuentra el dilema entre lo público y lo privado; espacios que convergen en el dilema de lo personal individual. Dicho dilema se manifiesta en el diario entre la "supuesta" necesidad de secreto que lo acompaña y el deseo (quizá no asumido) por su publicación, donde ya se transgrede el ámbito de lo íntimo. Estas cuestiones pueden resultar obsoletas en este tiempo de exposición constante de la vida; ya que la noción de lo íntimo y lo subjetivo se ha transformado con la aparición de las nuevas tecnologías, y es común, como dice Paula Sibilia (2008) en su libro La intimidad como espectáculo, "[...] exponer la propia intimidad en las vitrinas globales de la red" (p. 17). En este mismo estudio, ella describe cómo los diarios en la actualidad ya se publican en la web a modo de blogs, fotoblogs, videoblogs ${ }^{4}, \mathrm{y}$ cómo con el auge de la web 2.0 todos pasamos de ser espectadores a ser usuarios activos en la red: "Los e-mails son versiones actualizadas de las antiguas cartas que se escribían a mano con primorosa caligrafía $\mathrm{y}$, encapsuladas en sobres lacrados, atravesaban extensas geogra- fías. Y los blogs, ¿podría decirse que son meros upgrades de los viejos diarios íntimos?" (p. 18).

¿Dónde ubicar entonces el concepto de intimidad en un panorama como este? ¿Para qué hablar o postular siquiera esta palabra en medio de un mundo digitalizado en su imagen y en su escritura? Ya el concepto mismo puede resultar, como dije anteriormente, fosilizado entre tanto afán mediático por mostrarnos y por exponernos en la inmediatez del tiempo. Sin embargo, el mundo sigue escribiéndose y describiéndose en distintos formatos y lo que fue importante nunca deja de serlo aunque parezca un síntoma de la nostalgia.

La escritura diarista se retoma y se argumenta por sí misma en diversos aspectos de la vida individual y social de los individuos, la concepción de relatar y autorelatarnos la vida y sus aristas, está y estará vigente porque la necesitamos:

Los relatos autobiográficos constituyen hoy día una fuente altísima y diversificada para la exploración psicológica o para orientar la educación; son claves secretas para son- dear el submundo del hecho literario [...] sirven para repensar el pasado de la historia social; establecen conexiones entre las estructuras de los imaginarios sociales y la obra artística y, en fin, se vuelven precisos instrumentos analíticos e interpretativos en muchos y diferentes campos del saber (Russotto, 2008, p. 250).

El diario como objeto de análisis social y cultural, se ha mantenido vigente en estudios académicos para describir y argumentar las necesidades que han surgido en cada época de la historia; la escritura de tipo autobiográfica, en sus diversas formas, se ha mantenido vigente en este campo que, a pesar de pensarse individual y subjetiva, deja translucir los diversos modos de ser y de manifestarse del mundo colectivo. Tenemos el ejemplo de un concurso realizado en España en los años ochenta donde se convocó a todas las mujeres a participar con sus diarios, y el resultado de esto fue un testimonio social de las necesidades, problemáticas y sueños de las mujeres en este momento; un ejercicio único donde la escritura diarística es tomada como valor testimonial para conocer cómo viven y

\footnotetext{
$4 \quad$ El último trabajo de Lejeune fue precisamente analizar, junto a su hijo, algunos diarios íntimos expuestos en internet (para el 2005, habían ya cien millones de diarios, actualmente este número se debe haber triplicado) y en su último libro titulado: Cher é cram, Lejeune utiliza 27 ejemplos de diaristas que escriben en línea y que utilizan este recurso para escribir sus relatos autobiográficos.
} 
piensan las mujeres en un determinado momento histórico. ${ }^{5}$

Otro ejemplo de utilización del relato autobiográfico en el campo de la investigación social, es lo que hoy día se conoce como autoetnografía, una práctica cada vez más frecuente en las Ciencias Sociales y disciplinas afines. La autoetnografía es un intento por romper con los convencionalismos del análisis social e integrar este ejercicio a la creatividad que surge en la experiencia del trabajo con los otros. Entonces, la autoetnografía es una narración del yo, y es parte de un relato autobiográfico con fines de conocimiento tanto individual como social; como práctica de escritura en los trabajos de campo o en los estudios específicos de casos, apuesta no solo a lo creativo sino a una reflexión contextual donde el otro y sus circunstancias tiene una incidencia en el científico social y en su mundo interior que también es susceptible de ser transformado:

Las Prácticas Analíticas Creativas pueden ser una forma de resistencia a las modalidades del control social que marginan narraciones alternativas. En este sentido, permiten destacar las convenciones sociales junto con las opciones morales y éticas de la investigación. Siendo las ciencias humanas y sociales disciplinas que consisten en personas que estudian a personas, la tarea reflexiva se hace inexcusable (Lajeunesse, 2007, p. 268).

Dentro de lo que conocemos como autoetnografías, existen de muchos tipos: etnografías reflexivas, etnografías nativas o de miembros del grupo, narrativas personales evocativas, autobiografías, etnografías literarias o poéticas. A pesar de conservar cada una su especificidad, todas estas formas de escritura apelan a un encuentro con la subjetividad del investigador social, y requieren de él una apuesta por la autoobservación que es, en definitiva, un principio importante del relato autobiográfico:

Por supuesto esto no puede hacerse sin dificultades: la primera la calidad de la escritura, que debe ser más próxima a la literaria que a la que acostumbramos a emplear los científicos. Otras dificultades tienen que ver con el proceso y el procedimiento. Se requiere una mínima, pero compli- cada de lograr, honestidad emocional. Se requiere también una observación constante, una prudencia ética por todo lo que nos afecta e implica a terceras personas a las que solemos querer, y la disposición a que una serie de desconocidos lectores o miembros de tribunales académicos, accedan a parcelas íntimas de nuestra vida (Lajeunesse, 2007, p. 270).

Otro ejemplo en este ámbito de lo sociocultural son los diarios de viaje. Desde el siglo XIX (cuando los diarios de viaje eran objetivo principal de las publicaciones editoriales en muchos lugares de Europa), este recurso textual ha estado presente en la vida de occidente; este siglo fue el siglo del viaje, cuando aún el hombre veía el mundo como un lugar por explorar y los libros de viaje eran una forma de conocer y de describir los lugares visitados. Todo viajero era un descubridor; y la palabra impresa en su libreta viajera, una forma de hacer visible su viaje para los demás. Los diarios de viaje han sido y son, hoy día (bajo formatos y estilos recursivos diversos), un método de representación de la otredad; y con el auge de los estudios culturalistas y poscoloniales, se han estudiado

5 El libro titulado: Mi vida es mía (2001) es una recopilación de diarios de mujeres españolas en la década de los años ochenta y que se edita gracias al apoyo editorial de Anna Caballé y Joana Bonet, y gracias a una convocatoria en la revista Vanity Fair. El resultado es un estudio sociológico y cultural de las necesidades y pensamientos de las mujeres de la época. 
como documentos históricos y literarios $^{6}$ de suma importancia, para evidenciar cómo se han construido los imaginarios culturales que hoy día tenemos de las regiones, ciudades, países, continentes, etc. ${ }^{7}$

Otro de los aportes relevantes de la escritura diarística, se encuentra en el campo de la psicológica y el psicoanálisis, donde ha servido para observar, descubrir y analizar los campos de la subjetividad individual. Dice Ana Teresa Torres (2003), psicoanalista y escritora venezolana en su libro: El alma se hace de palabras, que tanto el diario como la terapia: "[...] necesitan de una retórica de sí mismo que le concede lugar, valor, función, espacio, en último caso, existencia. El ser, sin ninguna cualidad que atribuirse a sí mismo, se desvanece. Es apenas un objeto real, un organismo vivo, pero inexistente" (p. 20). En dicha retórica habita el sí mismo volcado a pensarse y reflexionarse como un ejercicio curativo y afectivo donde se pone en evidencia el carácter material de la palabra, su función de mediadora entre el extraño mundo inconsciente, y el vulnerable y censurado mundo consciente. Escribir, tanto como hablar, convoca el acto primario de contar esa historia que somos nosotros mismos. ¿Y para qué hacerlo? Para que el acto de nombrar libere y ayude a hacer consciente esa identidad huidiza y diversa que somos.

\section{El diario y la creación litera- ria}

De muchas maneras y en diversas situaciones, el diario ha acompañado a escritores, artistas, académicos de todas las épocas; ha servido como impulso imprescindible en esa gesta personal que es el trabajo creativo. A lo largo de la historia literaria, es evidente que muchos escritores consagrados o no, celebres o no, han portado $\mathrm{y}$ alimentado en algún momento de su vida un diario personal, $y$ lo han asumido en sus cotidianidades con diversas intencionalidades y motivaciones. Desde Henri-Frédéric Amiel hasta Frank Kafka, la historia cultural de Occidente avala este ejercicio de escritura como parte innegable de la creación literaria. Por ejemplo, cuando la obra aún es una posibilidad o cuando ni siquiera es un convencimiento real, la escritura diarista se muestra como posibilidad para ir gestando una idea o una reflexión que inspire o sostenga lo que más adelante se verá concretado en una obra artística. Dice Ricardo Piglia, escritor argentino, al inicio del documental sobre sus diarios": "Por supuesto que no hay nada más ridículo que la pretensión de registrar la propia vida, y sin embargo, estoy convencido que si no hubiera empezado esa tarde a escribirlo jamás habría escrito otra cosa" (Di Tella, 2015). Es un comentario contundente de un escritor consagrado de cuentos y novelas, y que durante toda su vida escribió diarios, dándole el valor último a sus escritos ocultos y sellados al público, pero que en definitiva estructuraron el sostén narrativo de su obra.

Muchas veces, el dilema del aspirante a escritor se sitúa entre el rechazo y la necesidad de este tipo de escritura; puesto que la escritura del diario se asume como un ejercicio marginal pero indispensable en medio del ejercicio creativo. Desde aquí, el diario no se concibe como una obra literaria central sino como un potencializador de la misma, como un vehícu-

$6 \quad$ Destaco aquí principalmente el trabajo de Marie Louise Pratt (2011) en su libro Ojos imperiales y el de Eduard Said (2013) en Orientalismo. Ambos libros son iconos de los estudios de libros de viaje y su función en las representaciones estereotipadas que hoy día imperan en nosotros de muchas culturas, y que a través de los relatos de viajeros "autorizados" y "letrados" son naturalizadas y se convierten en versiones totales de un gran cliché cultural.

$7 \quad$ Para un estudio más detallado sobre este tema, ver: González Otero, A. (julio-diciembre de 2016). Definiciones y aproximaciones teóricas al género de la literatura de viajes. La Palabra, (29), 65-78.

8 El documental 327 Cuadernos de Ricardo Piglia es dirigido por el cineasta argentino Andres Di Tella en el año 2015 y coincide con la publicación de los diarios de Emilio Renzi, alter ego del escritor. Este documental también coincide con la vuelta de Piglia a su país natal y la apuesta por develar su afición a la escritura diarista, que ejerce desde hace 58 años, y que suman 327 cuadernos de tapa negra e idénticos que dan nombre al documental. 
lo, como una catarsis necesaria donde nacen los monstruos y los ángeles del difícil arte de la creación artística.

En otros casos, se someten estas formas de escritura a un útil cuestionamiento, ya que el hecho de hacer una referencia narcisista constante que someta al yo a un lugar central tanto en la escritura o como en la vida diaria, se postula como posiblemente evitable. La escritora francesa Marguerite Yourcenar (2008) rechazaba la escritura intimista por considerarla un juego de presunción social o una alusión innecesaria, si lo que se desea es una conexión con el otro y su mundo:

Esa obsesión francesa por el culto a la persona (la de ellos) en la persona que habla o escribe, me asombra. Me atrevería a decir que la encuentro terriblemente pequeño burguesa. Yo, mi, mis...O todo está en todo, o nada vale la pena de ser hablado (p. 238).

Yourcenar me permite entrar en otro gran dilema que afronta el escritor; ya que, tradicionalmente, se asocia el acto creativo literario con la ficción, con la construcción de un mundo narrativo que poco o nada tiene que ver con su vida; puesto que aquellos actos creativos más cercanos a construir reflexiones personales o intimas, se podrían asociar a una falta de imaginación o una obsesión vacua por la propia persona. Me interesa esta postura que también considera las aristas, los prejuicios, las miradas divergentes que pueden aparecer frente al universo autobiográfico, y la desconfianza que muchos escritores manifiestan frente al hecho que la obra literaria nos agobie con sus excesos de yo.

Sin embargo, tanto como es posible y evidente que surja la desconfianza y el rechazo por la narrativa yoica, también puede surgir el deleite, la conexión instantánea; puesto que el otro, ese próximo que se narra y se autorelata, se nos asemeja en sus pequeños y grandes dolores, en sus breves alegrías. Ese emparentamiento, terapéutico y salvador, puede llegar a ser la razón de ser de la escritura autobiográfica:

La fascinación de la otredad se advierte discreta $\mathrm{y}$ potente en todas las expresiones materiales e imaginativas [...] En el fondo todo hablar y toda creación es una íntima indagación del otro. La alteridad se guarda en lo más recóndito de nuestro ser y todo le llama, le empuja a pronunciarse, a mostrarse, a decir quién es y cómo es (Ortiz, 1991, p. 63).

Es así que como lectores, creadores o simples seres comunes, buscamos y necesitamos saciar esas ansias de secreto, de develación de ese mundo inexplorado y locuaz que es el mundo del otro; y de alguna manera, intentar establecer o reestablecer el vínculo humano con esa, a veces, muda alteridad, desde ese básico sentir que nos une y que es nuestra condición humana, con todas sus luchas y soledades.

Escritores: ámbitos del yo y manías diaristas

Como se mencionó anteriormente, la creación literaria ha estado en continua relación con la tradición diarística desde diversos propósitos y motivaciones. Tenemos en Anaïs Nin, un ejemplo contundente de vinculación de la escritura del diario personal con el ejercicio literario. Esta escritora francesa de mitad del siglo XX, pone su obra central en la escritura diarista y los manuscritos originales de sus diarios, convertidos libros; son el núcleo de su obra. ${ }^{9}$ Fueron cincuenta años de su vida dedicados a describir, indagar y exponer sin reservas su interioridad de mujer escritora en sus diarios: "La fuente del diario es la obra de mi vida. Por mi parte,

$9 \quad$ Anaïs Nin inicia la escritura de su primer diario a temprana edad, cerca de los 12 años (Los diarios tempranos de Anaïs Nin 1914-1920). Este hábito se fortaleció en ella y continúo cultivando durante toda su vida. 
he experimentado todo y ahora estoy dispuesta a comenzar de nuevo" (Nin, 1981, p. 229). De Anaïs, podemos afirmar que apuesta por construir intimidad y diálogo con el mundo desde la escritura misma y desde un posicionamiento claro de su condición de mujer y de artista; dando una especial prioridad a las relaciones personales y sus intrincados rincones, para buscar comprenderlos a partir del ejercicio del diario.

Por otro lado, Anaïs Nin hace posible que su vida se convierta en un material indispensable en su escritura, fundiendo magistralmente el acto creativo con el acto de vivir. La escritura no se convierte entonces en un alejamiento de la vida o una evasión, ni para el autor ni para el lector; sino todo lo contrario, una fuerza vital que llama a vivir, a enfrentar el acto experiencial con todas sus consecuencias. Es fácil, entonces, ubicar a Anaïs es ese espacio de escritores para quienes la escritura diarista no es un acto marginal o paralelo ejercicio de escritura, sino que es asumido como centro neurálgico de la obra creativa.

En el caso de Julio Ramón Ribeyro y de Virginia Woolf, el diario personal toma otros senderos, no ya como centro de la obra creativa sino como un acompañante de la misma. En el prólogo a sus diarios: La tentación del fracaso (2014), Ribeyro expresa:
El diario está compuesto de una variedad muy grande de elementos y se da en tantos planos que es bastante difícil hacer un comentario global. Lo único que yo he recibido y que le da cierta continuidad es justamente ese desasosiego, esa sensación de desconcierto, de duda, esa constante interrogación sobre si lo que estoy escribiendo tiene valor, y hasta una especie de deseo de no realizar una obra definitiva, pues quizá eso me condenaría a no hacer nada más (p. 11).

Para Ribeyro, conocido por su obra cuentística, el ejercicio del diario se encuentra asociado a la interrogación por la obra y las dudas que se generan en el camino de la escritura y la consolidación del estilo; de igual forma, el diario para él no es la obra que desea publicar, sino, más bien, es la catarsis emocional de sus devaneos como escritor emergente. Para Ribeyro, es claro que la obra creativa está del lado de lo ficcional, pero recurre de manera constante a la escritura diarista para exponerse a sus pliegues personales, y así desahogar el escepticismo y la angustia que nacen del cuestionamiento de si realmente habrá para él un camino en el campo creativo, de si su escritura posee o no, el peso suficiente para alcanzar la transcendencia en el mundo literario.
Con Virginia Woolf, saltamos a una situación parecida, pero con un aura de mística artística; ya que su posición frente al diario personal, está valorada en espacios de significación creativa y trabajo académico. Para Woolf, el uso y escritura de un diario, tiene distintos caminos tanto en su reflexión como escritora, como en su reflexión como crítica literaria. De sus innumerables diarios, su marido Leonard Woolf selecciona de manera muy cuidadosa los pasajes asociados a su vida como escritora, para consolidarlos en un solo libro:

He leído cuidadosamente los 26 volúmenes del diario para extraer, y publicar ahora en este libro, prácticamente todo lo que se refiere a su propia actividad como escritora [...] En primer lugar, cierto número de pasajes donde salta a la vista que ella está utilizando el diario como método para practicar o poner a prueba el arte de escribir (Woolf, 1954, p. 10).

Gracias a este procedimiento realizado por él, nos llega para la posteridad el libro: Diario de una escritora, donde se encuentran registrados pasajes de una enorme calidad literaria, donde podemos hallar el germen de sus ideas, emociones, fijaciones creativas, inspiraciones cotidianas que luego las encontramos trasladadas y transformadas en 
sus novelas. De igual forma, encontramos en este diario comentarios y notas sobre sus lecturas, donde un gran número de escritores de la época tienen cabida, y Virginia intenta indagar sobre su valoración como artistas o poetas.

Ella también se enfrenta a ese importante dilema del diarista que se da entre el transcurrir del tiempo, la escritura y la vida. En una entrada que data del miércoles 19 de marzo, Virginia anota en su diario cómo la vida se asoma precoz y vertiginosa frente al ritmo reposado de la escritura: "La vida se acumula con tal rapidez que no me da tiempo para consignar el creciente tesoro de reflexiones, de ritmo no menos veloz, que suelo marcar, a medida que surgen, como dignas de ser anotadas aquí" (p. 55). En este dilema típico del diarista, está implícito esa necesidad casi que obsesiva por plasmar el registro de la experiencia vital en el diario; pero que jamás podrá alcanzarse, pues la pulsión vertiginosa de la existencia sobrepasa todo, incluso la escritura misma. Este dilema también se asocia a la existencia de la muerte que acosa los días, ya que, de alguna manera, escribir la vida es preservarla del olvido y de la decadencia de los días.
Virginia (como muchos otros escritores diaristas) se interroga sobre la razón de ser de su diario, qué tipo de anotaciones desea realizar y la connotación que estas "entradas" podrían traer para su vida personal:

Domingo de Pascua, 20 de Abril. ¿Qué clase de diario me gustaría que fuera el mío? Algo de textura poco compacta sin ser desaliñada, tan elástica como para contener todo lo que pasa por mi cabeza, tanto lo solemne, como lo insignificante y como lo bello (p. 24).

El diario se asume así, como un todo vital, elástico y compacto, un universo donde puede estar incluido lo simple y lo importante de una existencia. Es un mensaje de una escritora que atraviesa las épocas y que sirve para entender esa correlación directa que se plasma entre el mundo del diario y el mundo de todos los días. Una escritura que no se pierde en el artificio de las ficciones y los estilismos poéticos, sino que se integra más propiamente al ritmo pulsional de las horas para narrarlas y hacerlas pervivir en la memoria.

Apartándonos un poco del convencional uso cotidiano en los espacios privados del escritor, encontramos una modalidad que ido tomando fuerza en algunos escritores actuales ${ }^{10} \mathrm{y}$ es el uso ficcional del diario. En estos casos, el elemento ficcional le gana a los signos de veracidad y confesión que comúnmente nos dan los diarios personales, para integrar un potencial yo que se construye y se autorelata sin referentes con una realidad especifica: "Este uso ficcional del diario, dentro del marco de la estructura de la obra literaria, adquiere un sentido diferente porque renuncia a la comunicación de algo íntimo y secreto, para convertirse en literatura, en comunicación estética" (Hernández, 2016, p. 77). Desde aquí, el uso y potencial creativo del diario deviene ficción, utilizando el formato diario como un recurso estilístico y no como depósito de reflexión experiencial. En este espacio ficcional, el diario se transforma en una estrategia premeditada del escritor que advierte la idoneidad de este recurso narrativo para expresar la reflexión sobre el proceso mismo de la escritura en la voz narrativa. Por tanto, es usual que el narrador busque la diversificación y que se autoficcione sin miramientos, para jugar a disminuir la tenue línea entre la realidad y la ficción, y de esta manera, seguir conservando la magia de lo verosímil.

10 Tenemos el caso concreto de Ricardo Piglia con: Encuentro en Saint-Nazaire, uno de los relatos del libro: Prisión perpetua (2014); y, por supuesto, el escritor catalán: Enrique Vila -Matas con su último libro: Mac y su contratiempo (2017). Ambos libros son ejemplos concretos de la autoficción a través del diario personal y son ejercicios vanguardistas en su forma de construir metarelatos en la estructura narrativa. 


\section{El diario: procesos investiga- tivos y formación educativa}

En la actualidad, las investigaciones en educación han vuelto a mirar hacia el relato autobiográfico luego de periodos intercalados de interés y decaída. ${ }^{11}$ No obstante, las narraciones de este orden ocupan un lugar de tradición en la investigación cualitativa en educación. En el mundo de la pedagogía, se ha llamado principalmente "historias de vida" al método de investigación autobiográfico que enmarca la educación en el ámbito de la experiencia personal. Como lo dije anteriormente, con respecto al método autoetnográfico, la importancia que tiene el trabajo con seres humanos en los campos humanísticos ha derivado en asentar este tipo de propuestas que marcan una relevancia en los individuos y sus circunstancias particulares:

La razón principal para el uso de la narrativa en la investigación educativa es que los seres humanos somos organismos contadores de historias, organismos que, individual y socialmente vivimos vidas relatadas... la educación es la construcción y la reconstrucción de historias personales y sociales; tanto los profesores como los alumnos son contadores de historias y también personajes en las historias de los demás y en las suyas propias (Connelly y Clandini, citado en Sandín, 2003).

Podemos encontrar trabajos de este tipo en investigaciones que se han convertido en experiencias clásicas y relevantes, teniendo como punto de referencia los años 1980s y 1990s ${ }^{12}$, que han reservado un espacio en la historia de las metodologías en educación a la tradición narrativo-biográfica, la cual por, supuesto, incluye al diario personal. Por ejemplo, tenemos el caso de la investigación que realizó Miguel Zabalsa (2004) relatada en su libro: Diarios de Clase y, donde analiza diarios escritos por profesores en sus cursos de formación de maestros. En primera instancia, Zabalsa resalta el diario como un medio para la "reflexión de la propia práctica profesional" (p. 10). En el caso de los docentes ya posicionados en su labor e inmersos en las aulas, en rutinas de trabajo arduas y exigentes, la posibilidad de llevar un diario podría, en un principio, resultar un tanto complejo y exigente.

A pesar de esto, el hecho de nutrir un diario que acompañe la labor de enseñar, puede ser un ejercicio complementario y vivificante, un filtro necesario entre la vida personal y el trabajo en las aulas: "[...] los diarios permiten a los profesores revisar elementos de su mundo personal que frecuentemente permanecen ocultos de su propia percepción, mientras están involucrados en las acciones cotidianas del trabajo" (p. 17). La docencia es una labor que se gesta y se sostiene de una alteridad constante, lo que la hace susceptible a procesos de inter-

$11 \quad$ El tipo de investigación narrativo-biográfico hace su aparición y apuesta metodológica a principios de siglo XX cuando la inmigración europea a Estados Unidos dio lugar a estudios sociales centrados en las "historias de vida"; luego ocurre un resurgimiento importante en los años setenta con el psicoanálisis donde se establece un importante momento para las llamadas "psicobiografías". Progresivamente, el método autobiográfico ha ido consolidándose en Europa y en Latinoamérica en todos los campos de las Ciencias Humanas: Antropología, Sociología, Pedagogía, etcétera; para ir estableciendo su lugar de importancia frente a las investigaciones de corte racional y positivista.

12 "Connelly y Clandini (1995) nos hablan de los estudios ya clásicos de J. Dewey sobre el tiempo, la experiencia y la sociabilidad y del trabajo de Goodson (1988) sobre las historias de vida del profesorado y sobre los estudios del currículo en la enseñanza. Otras obras citadas, en relación a la profesionalización, son las Vidas y carreras del profesor (Ball y Goodson, 1985) y Carreras del profesor y mejora social (Huberman, 1988). La revisión de Elbaz (1988) de los estudios sobre el pensamiento del profesor creó un perfil de los enfoques más cercanos a la familia de los estudios narrativos. La monografía de Jackson (1968; 1991): La vida en las aulas significó un punto de partida para la literatura sobre historias de/sobre el profesorado [...] Algunos journals están dirigidos específicamente a la publicación de artículos que adoptan este enfoque de investigación, como el Oral History Review The Narrative Study of Lives [...] En el ámbito de la educación especial se han realizado algunos trabajos a través de historias de vida, y en la actualidad cobra un gran relieve en el estudio del fenómeno migratorio" (Sandín, 2003, p. 146). 
cambio personal nada fáciles de llevar y asumir; muchas veces, el estado emotivo que conlleva ese constante estado de alteridad, lo mismo que los conflictos, las desvanecías, los retos, etcétera, en la escritura diarista pueden ser analizados y racionalizados. El proceso reflexivo del espacio autobiográfico permite una sutil confrontación, una mirada introspectiva y sana sobre sí mismo; y el acto de la escritura surge como posibilidad de afrontar, observar y superar asuntos conflictivos de la cotidianidad, y no evadirlos u ocultarlos en el silencio y el desconocimiento. De esta manera, el ejercicio diarístico propicia y apuesta por el mejoramiento en las labores profesionales.

Desde el punto de vista del estudiante, los diarios, según Zabalsa, también conforman un método interesante, porque propician en el aula un diálogo fructífero entre estudiantes y profesores; ya que el proceso de escritura de un diario dentro de los cursos, permite construir un aprendizaje más receptivo y consciente:

Han resultado muy interesantes por sus efectos sobre el aprendizaje y el desarrollo de competencias metacognitivas en los estudiantes, las experiencias en que el diario es usado como instrumento de registro del proceso de aprendizaje que van siguiendo los alumnos. Se les pide que vayan reflejando en su diario la elaboración personal que van haciendo de lo que se va tratando en clase. (p. 27).

El lugar del aprendizaje ha dejado de ser un espacio pasivo, $y$, sin duda, el mundo subjetivo de los estudiantes está permeando de forma constante sus procesos educativos, la manera en cómo asimilan y elaboran el conocimiento. Por eso, el diario, al gestar una mirada en sus propios procesos como aprendices, resulta una apuesta interesante para construir una didáctica más inclusiva entre la vida personal y el mundo institucional.

El diario como proyecto de tipo educativo puede gestar una conciencia más clara de cómo aprendemos, cómo enseñamos o simplemente cómo estamos posicionados frente a estos roles. Sin embargo, más allá de ubicar los tipos de diario que existen a nivel educativo, puesto que los hay muchos y de diversos tipos, ${ }^{13}$ se intenta evidenciar cómo el diario activa procesos conscientes de reflexión y discernimiento frente a lo que enseñamos y a lo que aprendemos; cómo este tipo de escritura apuesta por la superación de asuntos de la subjetividad individual o con la alteridad cambiante, que se atraviesan en las labores de maestros y estudiantes, y que son relevantes para el buen desempeño de los procesos educativos.

En el campo de la investigación educativa, se cuenta con un ejemplo contemporáneo llamado: Investigación basada en las artes (IBA: Arts-Based Research), donde se toma como punto metodológico central las diversas expresiones artísticas, como las de tipo escritural (poesía, cuento, diarios personales, etcétera), de tipo audiovisual (fotografía, video, pintura), o sus combinaciones posibles, en lo que hoy conocemos como performance. Este tipo de propuesta ha ido fortaleciéndose en muchas academias de educación, principalmente la estadounidense, donde fue forjada. Este tipo de investigación parte de la narración autobiográfica para autodefinirse y apuesta

13 Existen en el campo educativo muchos diversos usos del diario en espacios con fines de aprendizaje; por ejemplo, los diarios en las clases de lenguas extranjeras, tenemos el ejemplo de clases ELE (Enseñanza de Español para Extranjeros), de la profesora Ariadna Saiz Mingo: "Género en ELE: Diarios de aprendizaje" (2010). Donde trabaja con mujeres inmigrantes que se encuentran en centros carcelarios y hace un uso del diario como un modo de reconocimiento del aprendizaje de competencias lingüísticas y su reconocimiento de los rasgos culturales que están implicados en la lengua heredada. De igual forma, en cursos virtuales o plataformas en la web, es bastante usual hoy día encontrar un diario de campo adscrito, en las plataformas virtuales como Moodle, por ejemplo, es una herramienta posible de instaurar como refuerzo o apoyo a los cursos presenciales, ejemplos de este tipo son innumerables y fáciles de encontrar en la web. 
por crear discursos reflexivos desde el yo para involucrar a todos los entes con los que el investigador trabaja diariamente: los lugares, las situaciones, los lectores, etcétera; y de esta manera, generar una investigación de tipo contextual donde todo cuenta, incluso los asuntos existenciales y subjetivos que pueden surgir frente a la investigación.

Desde esta posición, lo que se genera con la investigación narrativa no es estrictamente conocimiento, sino un texto, un relato, que alguien lee, y es precisamente ahí donde reside un nuevo nivel de relación fundamental: contar una historia que permita a otros contar (se) la suya. El objetivo no sería sólo capturar la realidad sino producir y desencadenar nuevos relatos (Hernández, 2008, p. 97).

Este enfoque investigativo también abre el espectro de posibilidades hacia los nuevos medios contemporáneos (lo audiovisual y performativo), e integra en la narración de tipo autobiográfico el uso de la imagen (fotografías, por ejemplo, acompañadas de textualidad), si así lo desea el investigador. ${ }^{14}$ En esa apertura que hemos comentado antes, la fusión del diario y sus extensas posibilidades, por ejemplo, la inclusión de lo visual como relato y no solo la escritura, se integra de manera positiva en esta propuesta.

\section{Integrando caminos: del dia- rio y sus arraigos}

Luego de realizado este breve recorrido por los distintos modos de ser y comportarse de la escritura diarista, podemos evidenciar las continuas recurrencias en torno a las potencialidades que ejerce este tipo de escritura en distintos campos de conocimiento y en la vida individual. Hacer visible las innumerables prácticas sociales y culturales donde el diario personal puede manifestarse y servir de apoyo, es poner en evidencia que la escritura autobiográfica en toda su dimensión ocupa un lugar importante tanto en los procesos socioculturales como en los procesos subjetivos y cognitivos de los individuos.

Desde el nivel literario, donde más se ha apostado por las escrituras del yo, vemos que la apuesta por el diario es histórica y sigue vigente en la tradición occidental; ya que como lo afirma Anna Caballé (1991):

Toda literatura es, pues, en este sentido literatura del yo (literatura of myself): nuestra vida es, como sabemos, una inmejorable fuente de escritura y remonta la tradición autobiográfica a los orígenes del hombre y la cultura [...] y así podemos afirmar que el hombre, cualquier hombre, vive con ese potencial autobiográfico que en realidad le define, puesto que le es consecuencia y se manifiesta de muy diversos modos, en la vida como en las obras (si las hay) (p. 10).

La vida toda, del creador o del hombre común, es por principio una autonarración constante, en la cotidianidad, la vida social, la vida íntima, los diálogos interiores, también en las creaciones que le sobrevivan. Lo problemático surge cuando los espacios de esta autonarración, de este pensarnos, de esta justa y necesaria subjetividad se anulan o se pierden entre los múltiples asuntos humanos. Es aquí cuando las escrituras autobiográficas cobran fuerza e impulso:

14 "Por su parte Mason (2002) y Sclater (2003) han puesto el énfasis en la relevancia de los métodos utilizados en la IBA, en la medida en que consideran que los dibujos, las historias o la utilización de viñetas o fotografías no sólo actúan como disparadores en una entrevista, sino que pueden también ayudar a conectar abstracciones ideológicas con situaciones específicas, al utilizar tanto elementos personales y colectivos de la experiencia cultural. Silverman (2000), a su vez, considera que la calidad de cualquier investigación es permitir acceder a lo que las personas hacen y no sólo a lo que dicen. En este sentido las artes llevan 'el hacer' al campo de investigación” (Hernández, 2008, p. 94). 
[...] la empresa autobiográfica viene a denunciar la alienación del hombre cotidiano cuyo vivir le impide vivir-se, explorar los repliegues del espacio interior, analizar los conflictos. La búsqueda y consecución de este espacio en el cuál pueda manifestarse aquel plus de significaciones que con frecuencia no agotó la vida pública del individuo [...] (Caballé, 1991, p. 11).

Es así como, el ejercicio del diario personal, el diario de aprendizaje, el diario del escritor, etcétera, ingresan en la vida de los seres para llenar el vacío de la falta de reflexión, y como una opción que mejore y dinamice los retos, los sueños, los conflictos, tanto consigo mismo como con sus semejantes. De igual forma, el diario como compañía espiritual, por llamarlo de algún modo, también se instaura en la vida para servir de figura simbólica que se adhiere a la subjetividad para construirla y hacerla existir en medio de los días. El diario como elemento material y físico tiene ya un componente de cuerpo que acompaña y dialoga con los otros elementos u objetos de la vida.

Con los ejemplos que he hemos expuesto a lo largo de este ensayo reflexivo, podemos corroborar las funciones diversas con que se manifiesta el ejercicio diarista, las cuales podríamos resumir así: el diario como gestor de alteridad y constructor de interioridad cumple una doble función que se manifiesta en la capacidad de la escritura como ejercicio autorreflexivo tanto de los procesos de creación literaria como de los procesos de aprendizaje educativos; el diario como escritura creativa, donde no solo es catalizador y retroalimentador de los viajes ficcionales sino que puede ser en sí mismo una empresa creativa con intencionalidades y estilo propio. También encontramos el diario como instrumento de apoyo para las buenas prácticas profesionales y la autorreflexión en los caminos investigativos de las Ciencias Humanas; ni hablar de todos esos diarios anónimos que se escriben en silencio, que jamás leeremos y estarán siempre en algún rincón de la vida del hombre común: alimentando el suceso del existir en el escritura.

Ahora bien, también se encuentran permeados de esta potencialidad del ejercicio diarista, los innumerables motivos concretos o abstractos con que los seres humanos pueden poblar la escritura y la imaginación que nace de su autorrelato personal. Aquí, el sendero de indagación se acaba para dar cabida una fuerza difícil de definir que es la fuerza de la personalidad que se nombra y se busca en la escritura; y es, como se menciona en el epígrafe, esa gran lucha de los seres por no perderse, por no desarraigarse del sí mismo que somos; sino por el contrario, de hacer un modesto intento para no naufragar entre los innumerables senderos de la existencia y hacer de la escritura un puente de encuentro con los rostros de nuestra propia interioridad.

Los horizontes investigativos de la escritura diarista siguen estando presentes en la actualidad, y están potencialmente activos en los diversos campos del conocimiento de las Ciencias Humanas y en la actualidad histórica del país. Un camino de investigación por desarrollar sería preguntar por el diario en nuestra historia literaria nacional: ¿Existe o no una tradición diarista? ¿Cómo se ha manifestado o por qué está ausente? De igual modo, desde las Ciencias Sociales existe un campo investigativo valioso por explorar: y son las huellas íntimas e históricas que ha dejado el conflicto armado, que podrían ser rescatadas a través del relato autobiográfico.

Finalmente, la exploración del fascinante universo de la intimidad humana es y será un objeto de búsqueda e interrogantes. En tiempos de crisis, la necesidad de la confesión como diría María Zambranoes una oportunidad para salir de la desesperación y coincidir de nuevo con la necesaria claridad del Ser. 


\section{Referencias}

Bayley, K. (1990). The Use of Diary Studies in Teacher Education Programs. En Richards \& Nunan (eds.), Second Language Teachers Education. Cambridge: Cambridge University Press.

Bonet, J., \& Caballé, A. (2001). Mi vida es mía. Madrid: Editorial Debolsillo.

Caballé, A. (1995). Narcisos de tinta: Ensayos sobre la literatura autobiográfica en lengua castellana. Madrid: Editorial Megazul.

Caballé, A. (1991). Figuras de la autobiografía. Revista Anthropos, 125. Barcelona: Anthropos.

Díaz, J. (1997). El diario como instrumento de investigación en los procesos de enseñanza-aprendizaje de segundas lenguas. Madrid: Centro Virtual Cervantes. Recuperado el 15 de enero de 2011, de http://cvc.cervantes.es/ensenanza/biblioteca_ele/asele/pdf/08/08_0269.pdf

Hernández, F. (2008). Investigación basada en las artes. Revista Educatio Siglo XXI, (26), 85-118.

Hernández, A. (2016). El diario de un escritor en Encuentro en Saint-Nazaire de Ricardo Piglia. La Palabra, (28), 75-90.

González Otero, A. (2016). Definiciones y aproximaciones teóricas al género de la literatura de viajes. La Palabra, (29), 65-78.

Guattari, F. (1995). Cartografías del deseo. España: La marca.

Juáres, G., Grischpun A., \& Walton, J. (productores), Di Tella, A (director). (2015). 327 Cuadernos. (documental). Argentina: Gema Films.

Foucault, M. (2002). La hermenéutica del sujeto. Buenos Aires: FCE.

Man, Paul de (1991). La autobiografía como desfiguración. Anthropos: Boletín de información y documentación, (29), 113-118.

Nin, A. (1981). Diario IV (1944-1947). Barcelona: Bruguera libro amigo.

Latorre, A. (1996). “El Diario como Instrumento de Reflexión del Profesor Novel”. Actas del III Congreso de E. F. de Facultades de Educación y XIV de Escuelas Universitarias de Magisterio. Guadalajara: Ed. Ferloprint.

Lajeunesse, F. (2007). Nuevas formas literarias para las ciencias sociales: el caso de la autoetnografía. Revista Athenea digital, (12), 262-271.

Lejeune, P. (1994). El pacto autobiográfico y otros estudios. Madrid: Megazul Endymion. 
Luque, A. (2016). El diario personal en literatura: teoría del diario literario. Revista Estudios de Literatura, 7, 273-306.

Russotto, M. (2008). Vidas malditas, vidas ingenuas, vidas artísticas. En Siglo del hombre (Ed.), Relatos autobiográficos y otras formas del yo. Bogotá: Universidad de los Andes.

Smith, S. (1991). Hacia una poética de la autobiografía de mujeres. En A. Loureiro (ed.), La autobiografía y sus problemas teóricos. Barcelona: Suplementos Anthropos.

Ortiz, A. (1991). La autobiografía como fascinación de la otredad. Revista Anthropos, 125. Barcelona: Anthropos.

Pratt, M. (2011). Ojos imperiales. México: Fondo de Cultura Económica.

Piglia, R. (2014). Prisión perpetúa. Barcelona: Anagrama.

Pinzón Manrique, H. (2014). La Literatura como InCorporación: El Cuerpo como Proceso. La Palabra, (24), 91-97.

Ribeyro, J. (2014). La tentación del fracaso. Barcelona: Seix Barral.

Sandín, M. (2003). Investigación cualitativa en educación. Madrid: McGraw-Hill.

Said, E. (2013). Orientalismo. Barcelona: Random House Mondadori.

Sibilia, P. (2008). La intimidad como espectáculo. México: Fondo de Cultura Económico.

Torres, A. (2003). El alma de hace de palabras. Cinco ensayos sobre escritura y psicoanálisis. Caracas: Blanca Pantin.

Vila Matas, E. (2017). Mac y su contratiempo. Barcelona: Seix Barral.

Woolf, V. (1954). Diario de una escritora. Buenos Aires: Editorial Sur.

Yourcenar, M. (2008). Con los ojos abiertos. Conversaciones con Matthieu Galey. Barcelona: Plataforma editorial.

Zabalza, M. (2004). Diarios de clase. Un instrumento de investigación y desarrollo profesional. Madrid: Narcea. 